\title{
Clause-Type, Force, and Normative Judgment in the Semantics of Imperatives
}

\author{
Nate Charlow
}

\section{Introduction}

Semantic theorizing about clause-types proceeds by identifying a canonical discourse role displayed by sentences of clause-type $T$, then assigning sentences of type $T$ semantic values thatperhaps together with independent pragmatic principles linking semantic values to discourse functions-allow them to play their canonical discourse role. Declaratives are assigned propositions as their semantic values to account, inter alia, for the canonical link between declaratives and the speech act of assertion. Interrogatives are assigned partitions as their semantic values to account, inter alia, for the canonical link between interrogatives and the speech act of questioning. In such theorizing, the canonical cognitive role displayed by sentences of type $T-$ e.g., the mental state canonically involved in accepting a sentence of type $T$-does not figure centrally in accounting for their meaning, though it may be derived as a kind of "downstream" (e.g., perlocutionary) effect of the canonical discourse role that is identified for $T$-sentences.

This is a successful and widely accepted methodology for semantic theorizing about clausetypes, which recent work on imperatives takes largely for granted. Portner's theory of imperatives is a well-known example (Portner 2004, 2007, 2012, forthcominga). The major competitor account to Portner's-the modal theory of imperatives championed most persuasively by Kaufmann, on which imperatives are assigned modal propositions as their semantic values (Schwager 2007; Kaufmann \& Schwager 2011; Kaufmann 2012) -is another.

This essay will describe an alternative methodology for theorizing about the semantics of imperatives-and clause-types more generally - on which their canonical cognitive role is treated as semantically fundamental-and encoded in the semantic value of an imperative-and their canonical discourse role is derived as a kind of "downstream" effect of their canonical cognitive role. It is worth mentioning upfront why this sort of methodology might be reasonably regarded as a non-starter in the case of imperatives. Strikingly, unlike declaratives and interrogatives, imperatives strongly resist embedding as the complements of attitude verbs. ${ }^{1}$

(1) a. Bernie knows that Hillary shut the door

b. Bernie knows whether Hillary shut the door

c. ${ }^{\star}$ Bernie knows [*that] shut the door, Hillary

Since there are precious few, if any, grammatical attitude constructions embedding imperatives as their complements, it would seem difficult to approach the semantics of imperatives by asking after the semantics of such constructions. ${ }^{2}$ Indeed, the difficulty of locating a canonical way of

*. For discussion and feedback I am grateful to Nick Asher, Chris Barker, Simon Charlow, Kit Fine, Daniel Fogal, Arno Goebel, Daniel Harris, Benj Hellie, Magda Kaufmann, Phil Kremer, Sven Lauer, Barbara Partee, Paul Portner, Jim Pryor, Mandy Simons, Eric Swanson, Rich Thomason, and Will Starr. The material in this paper has benefited from feedback from audiences at Carnegie Mellon, Cornell, Göttingen, Konstanz, New York University (several times), and Sinn und Bedeutung 17. The support of the Social Sciences and Humanities Research Council of Canada (Insight Grant \#435-2015-0423) is gratefully acknowledged.

1. In many languages (English included), imperatives appear to embed under speech act verbs (e.g. 'say') (see, e.g., Crnic \& Trinh 2008; Kaufmann \& Poschmann 2013). This does not vitiate the observation in the main text.

2. The classic discussion of the relation between the semantics of interrogatives and the semantics of attitude 
Nate Charlow

ascribing a psychological relation between an agent and an imperative sentence might be taken to suggest that imperatives lack anything like a canonical cognitive role at all.

I nevertheless will argue that this alternative methodology is worth pursuing in the case of imperatives (though not, of course, via the semantics of uninterpretable constructions like (1c)). The argument in this paper will be somewhat indirect, but the general idea is as follows. Accounts of imperative meaning like Portner's seem to suffer from explanatory deficits vis-à-vis imperatives embedded in conditionals and under quantifiers. A modal account like Kaufmann's offers an appealing alternative, but has its own explanatory deficits (owing mainly to its assignment of a proposition as the semantic content of an imperative). These latter deficits are most clear when one considers the canonical cognitive role for an imperative-a role that, while somewhat difficult to access via attitude ascription, is easier to access via philosophical psychology and cognitive science-to which a propositional account of the imperative seems to be committed.

This essay will motivate an alternative paradigm for theorizing about the semantics and pragmatics of imperatives. On the analysis advanced here, imperatives express contents that are both cognitively and semantically related to, but nevertheless distinct from, modal propositions (compare the position ultimately defended in Charlow 2014a). Imperatives, on this analysis, semantically encode features of planning that are modally specified. Uttering an imperative amounts to tokening this feature in discourse, and thereby proffering it for adoption by the audience. This analysis deals smoothly with the problems afflicting the accounts of Portner and Kaufmann. It also suggests an (in my view) appealing reorientation of clause-type theorizing in which the cognitive act of updating on a typed sentence plays a central role in theorizing about both its semantics and role in discourse.

\section{Clause-Type Analysis: A Very Short Overview}

Three major clause-types appear to be attested across natural languages: declarative, interrogative, and imperative. ${ }^{3}$

(2) a. Hillary shut the door. [Type: DEC]

b. Did Hillary shut the door? [Type: INT]

c. Shut the door, Hillary! [Type: IMP]

Clause-types tend to be seen as broadly conventional encodings of the clause's "force" (in a sense to be precisified). Conversely, the major types of "force" are presumed to have dedicated linguistic devices for their expression - a fact that suggests at least a partial explanation of the universality of the three major clause-types (see esp. Sadock \& Zwicky 1985; Portner 2004).

\section{$2.1 \quad$ Force}

In what sense is "force" encoded in a sentence's clause-type? The most natural reading of "force" would be Austin's (1975) notion of illocutionary force. ${ }^{4}$ Portner (2004), however, rejects the idea

ascriptions embedding interrogatives is Karttunen (1977). Cremers \& Chemla (2016) offer an updated assessment, proposing a revision to the standard the semantics of interrogatives motivated by considerations involving the semantics of attitude ascriptions embedding interrogatives.

3. An overview of clause-typing and its role in semantic and pragmatic theorizing is provided by Portner (2004), which in turns draws on Sadock \& Zwicky (1985); Ginzburg \& Sag (2001), among others. Universally attested clausetypes are here labeled as "major". Non-universally attested clause-types (like the Korean promissive) are generally assumed to derive their core semantic features from universally attested clause-types (like the imperative); from a semantic perspective, then, the Korean promissive, may be (and typically is) regarded as a sub-type of the imperative (see, e.g., Portner 2004: $\$ 4$ ).

4. This essay mostly elides the distinction between illocutionary force-a notion tied to speaker meaning in context-and what has been termed dynamic force-a notion tied to the informational change induced by updating 
that illocutionary force could be encoded at the level of clause-type, citing examples of sentences that exhibit an apparent mismatch of clause-type and illocutionary force, like:

(3) Can you pass the salt?

[Type: INT; Illocutionary Force: REQUEST]

But this would be premature. The literature is replete with analyses on which a speaker uttering a sentence like (3) performs a request by asking a question (Searle 1975; Asher \& Lascarides 2001; Charlow 2011: Ch. 3). On such analyses, the (primary) illocutionary act of asking a question may well be encoded in the clause-type of (3), while the (secondary, or, more commonly, indirect) illocutionary act of making a request may be derived from the primary illocutionary act, together with some form of conversational (e.g. Gricean) reasoning. ${ }^{5}$

This is important to appreciate, since many influential objections to specific clause-type analyses of the imperative begin with the observation that imperatives are well-suited for a wide range of illocutionary ends, beyond what we might call directive ends. Here are some standard examples (some borrowed from Wilson \& Sperber 1988).

(4) Come earlier (if you like) [PERMISsion]

(5) Have an apple! [invitation]

(6) Take the A-Train (to get to Harlem) [Instruction]

(7) Get well soon! [WeLL-wish]

(8) Throw it, I dare you! [DARE/THREAT]

Following Condoravdi \& Lauer (2012), we can provisionally understand an utterance of an imperative with a directive end as one that "(I) expresses a certain content related to the addressee's future actions; (II) conveys that the speaker wants the content to become reality; and (III) acts as an inducement for the addressee to bring about the content" $(38){ }^{6}$ It is clear that none of the above examples are naturally counted as directive uses of the imperative, in this sense.

It is sometimes alleged that, in light of such examples, any analysis of the imperative which conventionalizes its directive "force" cannot be correct. ${ }^{7}$ But this objection loses a great deal of its appeal, once a satisfying treatment of, e.g., (3) under the rubric of indirect speech acts is in view. Like (3), any of these sentences might naturally receive the indicated illocutionary interpretation, despite a conventional association with an altogether distinct illocutionary force.

a context or cognitive state on a sentence (Yalcin forthcoming). It is more accurate to say that clause-type analyses associate sentences - in virtue of associating them with canonical discourse roles - with a canonical dynamic (or para-illocutionary; see note 5) force, rather than illocutionary force proper. The account I go to develop will be in this spirit.

5. Asher \& Lascarides (2001) include the question expressed by (3) as part of what is meant, by the speaker, with an utterance of (3): the speaker literally performs both the illocutionary act of questioning and the illocutionary act of questioning with such an utterance (compare also Lepore \& Stone forthcoming). This idea has some limitations; I prefer, instead, to think of the question interpretation of (3) as being defeated, in a typical context, at some stage of conversational reasoning, with the request interpretation being supplied in its stead by abduction (Charlow 2011: Ch. 3). Whether the question survives as a bona fide illocutionary act, on my own analysis-or as a kind of paraillocutionary act-is a question of terminology.

6. I say "provisionally" because there are clearly directive uses of imperatives that do not convey that "the speaker wants the content to become reality," a point of which Condoravdi and Lauer are aware. (Consider a speaker known to have been coerced, against her own desires, to deliver an order to an addressee, and who does so with an imperative.) I suggest a different, more or less Gricean, understanding of direction in $\S_{5} .3$.

7. Representative statements may be found at Schwager (2007: 241); Condoravdi \& Lauer (2012: 40). 
Nate Charlow

\subsection{Individuating Types}

It is similarly important to emphasize the various shapes an account of the clause-type/force link might take. One (unappealing) option is that clause-type is an abstraction from force, clause-type being simply a way of categorizing sentences according to an independently attested canonical discourse role or force. But this risks conflating two sentences of manifestly different clause-types that share a discourse role, like ( $2 \mathrm{~b})$ and its performative analogue (9):

(9) I hereby query whether Hillary shut the door

More plausibly, instantiation of a clause-type $T$ is the feature in virtue of which sentences of type $T$ are associated by the grammar with a canonical discourse role or force. What type of feature would this be-morphosyntactic or semantic? Perhaps sentences of type $T$ are so-typed in virtue of containing a silent force marker in their syntax (e.g., Han 1998), in which case clausal typing falls plausibly within the domain of Universal Grammar. Perhaps sentences of type $T$ are so-typed according to language-specific morphosyntactic properties (like wh-movement or a null subject and uninflected verb), in which case clausal typing falls plausibly within the domain of the language-specific grammar. Finally, perhaps sentences of type $T$ are so-typed according to features of their semantic values - perhaps according to the model-theoretic type of semantic value, or something more fine-grained still.

Clause-type analysis, per se, requires none of these options. The common metalinguistic representation of a typed clause with a sentential operator scoping over an untyped clause-e.g., representing the sentences in (2) using "force operators" (like the Fregean assertion operator $\vdash$, a question operator?, or an imperative operator !) scoping over untyped "sentence radicals"-is, in fact, neutral between the understandings of clause-typological individuation just described. In particular, such a representation —in a regimented formal metalanguage, à la Montague (1973) need not (and generally does not) purport to realistically represent the actual syntax of the corresponding sentence in natural language.

This a well-appreciated point in the literature. A related, but somewhat less well-appreciated, point is that distinct clause-types might be represented in the metalanguage as varying, not along the force operator dimension, but rather along another dimension altogether. It is, for instance, open to us to represent one clause-type as somehow parasitic or dependent on another clausetype. Imperatives, for example, might be represented in the metalanguage as being derived from related (e.g., modal) declaratives-perhaps, as I will ultimately suggest, by some type-shifting operation - without object-language imperatives being actually derived from modal declaratives, or in fact containing a modal in their morphosyntax at all.

This flexibility allows a certain kind of theorist (mine) to prescind from many of the questions that have lately animated the linguistic literature on imperatives. Do imperatives contain modals? ${ }^{8}$ Are there force operators in syntax? I do not propose to answer these questions here. Can the semantics of imperatives be theorized about, under the rubric of clause-type analysis, while availing ourselves of the tools of our best theories of linguistic modality? Could imperatives have a "modal semantics" - even while failing to display some of the hallmarks of linguistic modality? That will mostly depend on the explanatory attractions of the semantics. I will later suggest that there are enough for us to respond to these questions with a cautious yes. ${ }^{9}$

8. Kaufmann argues yes (see esp. Kaufmann 2012). Portner argues no (see esp. Portner 2007). von Fintel \& Iatridou (2009, forthcoming) side tentatively with Portner.

9. Roberts (2015) represents another account in this general vein. 


\subsection{Semantic Value and Content}

Since clause-type analysis aspires to provide a semantics for-or at least a rubric for theorizing about the semantics of-typed clauses, it is important to know what type of semantic theory is supposed to be on offer. There are at least two options. The program of modern Generative Semantics is generally understood as providing a compositional characterization of a sentence's semantic value, with an eye to revealing what semantic competence with respect to that sentence consists in. Semantic theorizing in more philosophical circles tends to aim at something different: a (possibly noncompositional) characterization of the (typically propositional) content conventionally proffered by a sincere utterance of a sentence. ${ }^{10}$ What type of semantic theorizing is clause-type analysis engaged in?

Clause-type analyses-like that of Portner, as well as, for example, Roberts (1996, 2015, forthcoming) - should generally be read as offering a semantic analysis in the second sense (which is, of course, not to say that they involve any sort of rejection of the Generative program). Portner describes a tight relationship between (i) model-theoretic type of semantic value and (ii) canonical discourse role. The semantic values of declaratives-propositions-are fit for the illocutionary act of assertion (and when tokened in discourse are added by default to the Common Ground); the semantic values of interrogatives-questions-are fit for the illocutionary act of questioning (and when tokened in discourse are added by default to the list of Questions under Discussion, à la Roberts (1996)). It is well-understood that assertoric content often diverges from compositional semantic value; indeed for many purposes it does not make much sense to say that the compositional semantic value of a declarative is a proposition, in the ordinary sense-i.e. a thing fit for the content of assertion and belief, and the object of credence-at all (Lewis 1980; Ninan 2010). Portner (and Roberts) thus seem to be giving analyses that link conventionally proffered contents to canonical discourse roles.

Clause-type theorizing, so understood, does place constraints on compositional semantic theorizing-and vice versa-since there is assumed to be some sort of determinative relation holding between compositional semantic value and conventionally proffered content. But the constraints are plausibly looser than is ordinarily assumed in the literature on imperatives. Consider the possibility that (i) the conventionally proffered content of an imperative is modeled with a modal operator, (ii) no corresponding modal operator is witnessed in our representation of the imperative's compositional semantic value. ${ }^{11}$ Such a proposal would free the clause-type theorist to explore the conventionally proffered content of an imperative via a modally loaded account of its canonical discourse role-or better, as I will ultimately suggest, a modally loaded account of its its canonical cognitive role-while sidestepping definite commitments in the realm of compositional semantics.

\subsection{Canonical Cognitive Role}

We've seen that clause-type analysis is naturally understood as offering a rubric for theorizing about the content conventionally proffered by an utterance of a typed clause. Conventionally proffered contents are posited to explain, inter alia, what is said by an utterance in a standard context of utterance. Conventionally proffered contents are, in other words, things proffered by

10. On the distinction, see Lewis (1980); Ninan (2010); Yalcin (2014). Though notions like 'content' have unclear purchase in certain (e.g., dynamic) frameworks, such frameworks do traffic in notions like conventionally proffered meanings (in dynamic frameworks, these tend to be modeled as update instructions).

11. Such a proposal might raise the suspicion that the imperative's conventionally proffered content stands in an obscure relationship to its compositional semantic value. The alleged obscurity might be remedied with, for example, an account of the determinative relation that holds between these entities, which does not amount to simple identity. I can provide no such account here, since I take basic questions regarding the compositional semantic contribution of the imperative to be unsettled. 
speakers for addition to the Common Ground, for cognitive adoption-acceptance-by conversational participants, and so on.

(What is acceptance? I understand update and acceptance as loosely interdefinable: acceptance of content $C$ may be understood in terms of redundant update on $C$, while updating on $C$ is a state that generally induces acceptance of $C$. Acceptance of an interrogative is, roughly, the sort of state in which updating on that interrogative would be redundant. ${ }^{12}$ )

Clause-type analysis suggests a link between the semantic content of a typed clause and the attitude typically induced by an utterance of that clause. As the content of a typed clause determines a canonical discourse role-whatever discourse role is associated, by default, with the absorption of such a content into the context-it also determines a canonical cognitive rolewhatever cognitive role is associated, by default, with update on that content. Declaratives, as devices for expressing propositions, are linked to propositional attitudes-attitudes taking embedded declaratives as their complements, and which paradigmatically (in, e.g., the case of belief) ascribe acceptance of the declarative's content to the attitude-ascription's subject. Interrogatives, as devices for expressing questions, are linked to question-directed attitudes-attitudes taking embedded interrogatives as their complements, and which paradigmatically (in, e.g., the case of wondering) ascribe acceptance of an interrogative content to the attitude ascription's subject.

The link between an analysis of clause-type $T$ and attitudes taking sentences of type $T$ as complements must be stated with care, since (i) propositional attitude-ascriptions (e.g., desireascriptions) need not ascribe acceptance of a propositional content to their subjects; (ii) interrogative attitude-ascriptions (e.g., certain forms of knowledge-wh-ascription) need not ascribe acceptance of an interrogative content, in the just-described sense, to their subjects. ${ }^{13}$

Such attitudes are not linked in the envisioned way to the posited canonical discourse role for declaratives or interrogatives. Instead, clause-type analysis suggests an understanding of the attitudes that are induced, by default, when an agent updates on the conventionally proffered content of a typed clause: a "core" propositional attitude, like belief (or something close, like conditionalization of one's probabilities on a propositional content), in the case of declaratives; a "core" interrogative attitude, like issue-sensitivity (or something close, like wondering wh-), in the case of interrogatives. In this way, a sentence's canonical cognitive role may be derived from its canonical discourse role via its conventionally proffered content.

12. A useful comparison is with Stalnaker (2002). Stalnaker uses 'acceptance' to delimit "a category of propositional attitudes and methodological stances toward a proposition, a category that includes belief, but also some attitudes (presumption, assumption, acceptance for the purposes of an argument or an inquiry) that contrast with belief, and with each other" (716). Like Stalnaker's notion, my notion of acceptance is broader than belief: one might accept that $p$ (in the context of, say, a supposition), without believing that $p$; in my idiom, this means that, in the context of the relevant supposition, updating on $p$ would be redundant. Unlike Stalnaker's notion, my notion of acceptance encompasses attitudes (like wondering) whose functional role is not to be understood as serving up a propositional content for the sake of some cognitive activity.

13. Point (i) is obvious. On point (ii), I do not mean that, since knowledge-wh ascriptions ascribe knowledge to their subjects, they do not ascribe uncertainty, hence do not ascribe acceptance of an interrogative content. Acceptance of an interrogative content is to be sharply distinguished from uncertainty about how to answer the question expressed by the interrogative: uncertainty about some proposition does not imply acceptance of a corresponding interrogative content, nor does acceptance of an interrogative content imply uncertainty about its propositional answers. A subject can recognize the issue expressed by the embedded interrogative-can partition her information along the lines suggested by the interrogative-even when she is not uncertain about how to resolve it; example $(1 \mathrm{~b})$ is naturally read in this manner. Consider, however, non-exhaustive (e.g., mention-some) readings of embedded interrogatives.

(10) Maria knows where to buy an Italian newspaper

(11) Maria knows how to play guitar

It is enough for the truth of (10) that when Maria wants an Italian newspaper, she reliably will go to a place where an Italian newspaper is available for purchase. Similarly a sufficient condition for (11) is that Maria is able to play guitar. Asking Maria where to buy an Italian newspaper, or how to play guitar, is liable to raise cognitively novel issues for her. Thanks here to Simon Charlow. 


\section{Portner}

This section and the next will situate the accounts of imperatives developed by Paul Portner and Magdalena Kaufmann within the understanding of clause-type analysis sketched in this section. I will raise some (more or less) empirical doubts about both types of account.

\subsection{Dynamic Pragmatics}

Portner develops his analysis of the imperative within the framework of what he terms Dynamic Pragmatics. ${ }^{14}$ His description of the program's key tenets:

\section{Dynamic Pragmatics}

i. Sentences have standard static semantic values.

ii. The communicative effect of utterances in discourse is modeled as the effect they have on the discourse context.

iii. The effect of a particular sentence is determined by pragmatic principles on the basis of the sentence's form or semantics (Portner forthcominga: PAGE)

He links Dynamic Pragmatics to clause-type analysis as follows:

\section{Semantic Values}

i. The semantic value of a declarative sentence is a proposition.

ii. The semantic value of an interrogative sentence is a set of propositions.

iii. The semantic value of an imperative sentence is a property restricted to one individual (the addressee). (ibid., PAGE)

\section{Force Assignment}

The force of a root sentence $S$ is a function updating the discourse context by adding $\llbracket S \rrbracket$ to the component of the context which is a set of objects from the same semantic domain as $\llbracket S \rrbracket$ (ibid., PAGE)

Dynamic Pragmatics, as pursued by Portner, involves a specific form of clause-type analysis, in the sense we have sketched. Sentences are assigned a clause-type representation according to the model-theoretic type of their conventionally proffered content. A sentence's canonical discourse role is derived from its clause-type representation: given an utterance of a sentence at a context, a parameter of that context is selected for update according to the semantic type of its conventionally proffered content. The canonical discourse role of a sentence (with conventionally proffered content of semantic type $\tau$ ) is the addition of its conventionally proffered content to a contextual parameter that records the conventionally proffered contents of utterances-when, but only when, that content is of type $\tau$.

It is important to remember that Portner does not encode illocutionary force at the level of clause-type: addition of a content of propositional type to a contextual parameter that records contents of propositional type-i.e., a set of propositions-may correspond to assertion (when the relevant contextual parameter is the Common Ground), but to a distinct illocutionary act as well (when the relevant set of propositions is distinguished from the Common Ground). More generally, the illocutionary force of an utterance of a typed clause with conventionally proffered content of semantic type $\tau$ is, for Portner, a function, not only of its clause-type, but also which record (or records) of $\tau$-type contents the utterance targets for update.

14. This exposition draws from Portner (2004, 2007, 2012, forthcominga). 


\subsection{Many To-Do Lists}

The semantic value of an imperative is, for Portner, an addressee-restricted property:

$$
\llbracket \text { shut the door } ! \rrbracket^{c}=\lambda x: x=\text { addressee } . x \text { shuts the door }
$$

By the Force Assignment principle, the force of uttering an imperative is to add the utterance's semantic value to a dedicated contextual record: a set of entities of the same semantic type. Portner dubs such sets "To-Do Lists," and introduces a To-Do List function-typed, roughly, as a function from individuals into their To-Do Lists-as a novel parameter of the context (Portner 2004, 2007, 2012). ${ }^{15}$ Within this framework, Portner attempts to account for the wide varieties in illocutionary force associated with imperative utterances by appeal to one of the following:

- The existence of different species of commitment within an individual's To-Do List (e.g., deontic, legal, bouletic, teleological). Commands interpretations, perhaps, involve updates to an agent's deontic To-Do's. Suggestion interpretations, perhaps, involve updates to her bouletic To-Do's. (Portner 2007)

- Contextual factors. A permission interpretation of an imperative, for example, is claimed to arise in contexts where property that is inconsistent with the property expressed by the imperative is already present on the addressee's To-Do List. (Portner 2012)

A signal attraction of the account is what we might call its illocutionary "flexibility" - its broad structural adaptability to uses of imperatives that have stymied competitor accounts. As an illustration, Portner (forthcominga) jettisons the assumption that there is a single To-Do List for each individual. The objective here is to account for a further aspect of variability in imperative usage: variability in imperative strength, of the sort attested in the following minimal pair:
a. Take a seat ${ }^{\Uparrow}[$ WEAK]
b. Take a seat ${ }^{\Downarrow}$ [STRONG]

Rising imperatives are naturally associated with invitations or suggestions, falling imperatives with orders or directives. ${ }^{16}$

Portner's strategy here will seem familiar: illocutionary variability is variation in which ToDo List(s) are selected for update, as a function of the imperative's intonational profile.

- Rising imperatives propose to add their content to a To-Do List that represents the addressee's representation of her own commitments.

- Falling imperatives propose to add their content to a To-Do List that represents the speaker's representation of the addressee's commitments.

Portner's account achieves a remarkable degree of coverage-a degree that is, in principle, indefinitely extensible, through the further proliferation of To-Do Lists-over the wide range of illocutionary variety attested in imperative utterances. But, I will now argue, it is has prima facie

\footnotetext{
15. The conceptual foundations for a To-Do List account-in particular, the functional role of the To-Do List in a general account of practical rationality and conversation-seem to merit further consideration. Portner (forthcominga) writes that "the to-do list defines a pre-order over the context set and an action by participant $p$ is deemed rational and cooperative if it tends to make it the case that the actual world is maximally highly ranked according to $p$ 's to-do list" (see also Portner 2007: 358). Rationality, as I understand it, is tied to an agent's maximization of subjective expected utility, which has little-as best I can see-to do with her To-Do List.

16. The association is not conventional. Rising imperatives can, for example, receive extremely strong interpretations (don't you dare ${ }^{\Uparrow}$ ). Portner need not commit himself to any such conventional association in order to display the illocutionary flexibility of the clause-type analysis he favors.
} 
difficulty accounting, even in principle, for two kinds of embeddings of the imperative: as the matrix clause of a conditional, and under apparently quantificational operators. ${ }^{17}$

\subsection{Conditional Imperatives}

Conditional imperatives like (13) exhibit the familiar characteristics of ordinary, or unconditional, imperatives (for a helpful catalogue, see Roberts 2015).

(13) If it starts to rain, shut the door

In particular, conditional imperatives, like ordinary imperatives, tend strongly to have a directive function in discourse (which can, as ever, be modulated by contextual variation, intonation, and so on). We can "operationalize" this directive function by noticing that utterances of imperatives of any type tend to make true (or else be grounded in the truth of) a corresponding modal statement like (14). ${ }^{18}$

(14) If it starts to rain, you [should/must] the door

From the perspective of clause-type analysis, the shared characteristics of conditional and ordinary imperatives might seem unremarkable. Indicative conditionals are standardly assigned a clause-type as a function of the clause type of their main clause (i.e., consequent) (Bhatt \& Pancheva 2006), while indicative antecedents are surmised to express a kind of restrictive operation on the semantic value of the main clause (à la Kratzer 1981, 1991). ${ }^{19}$ From this perspective, conditional imperatives are nothing special: conditional imperatives are imperatives, and propose some sort of property-restricted in some fashion by their antecedents-for addition to the addressee's To-Do List(s).

In fact, however, Portner's Dynamic Pragmatic account sits uneasily with these pieces of orthodoxy. If a sentence like (13) is typed as imperative, its semantic value will be given by a logical form of roughly the shape in (15):

(15) [if it starts to rain $]\left[\lambda x_{\text {addressee }}[x\right.$ shuts the door $\left.]\right]$

Such a logical form is, however, problematic: there is apparently no operator present for the if-clause to restrict. ${ }^{20}$ If this is how conditional imperatives are represented at logical form, conditional imperatives are semantically ill-formed.

But let us bracket this worry, and assume that a logical form of the right type is computable

17. For earlier discussion of this type of data for quantified imperatives, see Charlow (2010: 230-2); (2011: §4.4.7). On conditional imperatives, see Charlow (2011: §4.5); (2014a: 652ff); (2014b: 546ff).

18. The connection between imperatives and corresponding modal statements is perhaps their most carefully studied property. A chronological sampling of references that treat this connection as theoretically central: Åqvist (1964); Han (1998); Aloni (2007); Schwager (2007); Portner (2007); Charlow (2011); Kaufmann (2012); Charlow (2014a); Starr (forthcoming). Portner (forthcominga) makes the very interesting observation that a judgment of the truth of (14) can both justify and be justified by a speaker's utterance of (13), which I have taken on here.

19. Kaufmann (2012) argues convincingly that examples like (13) are bona fide "hypothetical" indicative conditionals, i.e., not relevance (biscuit) conditionals or factual (echoic) conditionals. On my possibly idiosyncratic understanding of the hypothetical/non-hypothetical contrast, the antecedents of hypothetical conditionals contribute their semantic values to the computation of the semantic value of the entire conditional structure, while the antecedents of non-hypothetical conditionals perform some other non-semantic function (e.g., signaling relevance).

20. Ordinarily, Kratzer (1991) suggests, we may posit an unpronounced epistemic necessity modal so that the compositional function of the if-clause may be fulfilled. This suggestion is a non-starter for conditional imperatives: quite unlike ordinary imperatives, this would wrongly construe directive uses of conditional imperatives as directives concerning features of an epistemic state, rather than the addressee's actions (vis-à-vis, say, the door). 
for (13). This property will have roughly the shape in (16):

$$
\lambda x_{\text {addressee }}[x \text { shuts the door if it starts to rain }]
$$

Such a content, being of the semantic type addressee-restricted property, is predicted, in Portner's Dynamic Pragmatics, to have the discourse profile typical of other property-type semantic values: its canonical discourse function is to be added to some set of property-type semantic values, i.e., one or more of the To-Do Lists made available by the context of utterance.

This prediction is incorrect. ${ }^{21}$ Directive uses of conditional imperatives, as noted above, tend to make true (or else be grounded in the truth of) corresponding modal statements. But the truth condition of a modalized conditional like (14) is not the presence of the property in (16)or of a proposition derived from that property, to the effect that the addressee shuts the door if it starts to rain - on the ordering source relevant for the interpretation of the matrix modal of (14). According to the basic analysis of Kratzer (1981), the truth condition of (14) is that the most highly ranked (according to the ordering source) contextually relevant possibilities are ones in which you shut the door. The mere presence of the property in (16) on an ordering source is not sufficient for this (if, for example, an incompatible property is already present in the ordering source, so that the ordering source, once updated with the relevant property, is indifferent or lacks a preference between shutting and not shutting the door in the event of rain) (a point also noted in Charlow (2011: 15ff); Condoravdi \& Lauer (2012: 56)). ${ }^{22}$

But let us bracket this worry, too, and ask simply what sort of property is (16) supposed to $b e$ ? Trivially, the property of making a conditional true. What kind of conditional? I know of no option other than the material conditional. ${ }^{23}$ Now consider the sequence in (17):

a. Don't rob me.

b. If you do, leave my phone. $\lambda x[x$ does not rob speaker $]$ $\lambda x[x$ leaves speaker's phone if $x$ robs speaker $]$

This is as unremarkable a sequence of imperatives as one is likely to find.

Interpreted as the property of making a material conditional true, however, the addressee's satisfaction of the property in (17b) is logically guaranteed by the addressee's satisfaction of the property in (17a). In other words, (17b) adds a weaker demand to the relevant To-Do List(s) than

21. Portner (forthcomingb) has pondered the adoption a dynamic account of conditional imperatives, like the ones defended in Charlow (2011); Starr (forthcoming). A dynamic account would, indeed, be well-positioned to accommodate the data presented in this section. This option is, however, foreclosed to Portner, given his broader programmatic commitments to the shape of clause-type theorizing (cf. Charlow 2014a: 653). For the Dynamic Pragmaticist, "sentences have standard static semantic values"; dynamic or discourse-level meanings must be derived by application of the Force Assignment principle. More generally, a Portnerian Dynamic Pragmatic account is distinguished by assigning sentences theoretically "minimal" semantic values: imperatives denote properties because they are null-subject VPs, and null-subject VPs denote properties. If conditional imperatives turn out not to denote properties-something that would be required for Portner to avoid the argument I am making here-it would seem that the Dynamic Pragmatic program, as presented by Portner, is untenable after all.

22. Thus Portner predicts the possible coherence-in at least one sense of coherence-of a discourse sequence that involves an imperative requiring $p$ and an expression of permission allowing $\neg p$. There is, I argue elsewhere, strong evidence that such sequences are semantically disallowed-literally contradictory (see, e.g., Charlow 2014a: 653-4). It is possible for Portner to avoid this, by incorporating a revision procedure into his account, so that updating a To-Do List $t d l$ on an imperative requiring $p$ makes it the case that $t d l$ requires $p$, as in Starr (forthcoming). Such a revision procedure, in my view, takes us outside the realm of semantic/pragmatic theorizing (Charlow 2014a: 654-6).

23. As I mentioned in note 20 , construing directive uses of conditional imperatives as directives concerning an epistemic state misconstrues what we might call their "subject-matter". Indicative conditionals are, it is now widely accepted, semantically evaluated relative to epistemic-or, more neutrally, informational-states. It follows that we cannot construe the conditional embedded in (16) as an indicative conditional. 
(17a) (Charlow 2014a: 625-6). Such a discourse move is, however, ordinarily quite marked: ${ }^{24}$

(18) a. Leave my phone.

b. \#If you rob me, leave my phone.

(19) a. Don't take my possessions.

b. \#Don't take my phone.

The reason for this seems clear enough: conditional on having expressed an expectation that someone see to it that $\phi$, expressing a weakened expectation (i.e., expressing the expectation that someone see to it that $\psi$ when $\phi$ strictly entails $\psi$ ) is pragmatically unavailable (except, perhaps, given explicit or implicit retraction of the earlier-expressed stronger expectation). But if this holds true for (18) and (19), why would it not hold true for (17)?

I did not, of course, invent this sort of case-it is borrowed from the literature on ContraryTo-Duty (or Second-Best) Obligations, which recent sophisticated treatments have analyzed utilizing the information-sensitivity of expressions like deontic modals (and the ability of indicative antecedents to shift the information against which information-sensitive material in their main clauses is evaluated) (see, e.g., Willer 2014). Conditional imperatives, it is worth noting, apparently display a sort of information-sensitivity that is quite similar to that exhibited by deontic conditionals. ${ }^{25}$ Consider the following example (from Charlow 2014a: 625): ${ }^{26}$

(20) a. If it's going to rain, take the umbrella (but leave the sunglasses)

b. If it's not going to rain, take the sunglasses (but leave the umbrella)

c. Bring both (...since we don't know)

Sequence (20) is, to my ear, unremarkable: (20a) and (2ob) can be offered as conditional advice the day before the referenced outing; (20c) can be offered as additional advice the day of the outing, without any sense that the speaker is changing her mind or retracting her conditional advice. (Notice that if, subsequent to the utterance of (20c), it begins to look as if it's going to rain, the speaker's advice to take the umbrella will still apply to the addressee.) However, the properties expressed by these three imperatives, on my understanding of a Portnerian analysis of conditional imperatives, are known by a competent speaker to be inconsistent-jointly logically unsatisfiable by any agent. It is mysterious how a speaker could-without manifest incoherence-propose such inconsistent properties for addition to the same To-Do List.

\subsection{Quantified Imperatives}

Quantified imperatives like (21) also exhibit familiar characteristics of ordinary imperatives.

(21) Everyone ${ }_{i}$ take $[\text { his/her/their }]_{i}$ seat

In particular, quantified imperatives tend strongly to have a directive function in discourse (subject to the usual caveats). As before, one way of "operationalizing" this directive function is to notice that utterances of quantified imperatives tend to make true (or else be grounded in the

24. Examples of allegedly "valid imperative inferences" adduced in the literature (in e.g. Vranas 2008, 2010; Parsons 2013) are, for this very reason, generally quite marked.

25. For my own understanding of information-sensitivity in deontic conditionals, see Charlow (2013a). A hallmark of information-sensitivity, on this sort of view, as noted by Willer (2012) (see also Yalcin 2012b), is the apparent failure of modus tollens for natural language indicatives with information-sensitive consequents: rejection of the consequent of such a conditional does not commit one to rejection of its antecedent (as seems clear from sequence (20)).

26. It is also worth mentioning that it is possible to recreate Kolodny \& MacFarlane (2010)'s Miner Paradox-a core data point in the case for information-sensitivity (see, among many others, Charlow 2013b; Cariani et al. 2013; Carr 2015) - with (weak) imperative, rather than deontic, conditionals. For the case, see Charlow (2010: 227). 
truth of) a corresponding modal statement like (22).

(22) Everyone $_{i}\left[\right.$ should/must] take $[\text { his/her/their }]_{i}$ seat

A logical form of the right type would seem to be computable for (21):

(23) $\lambda x_{\text {addressee }}[x$ takes $x$ 's seat $]$

Such a property would then be added, as indicated by the quantifier phrase, to each (relevant) $t d l(x)$, for each addressee $x$.

This is a prima facie satisfactory story about the canonical discourse role for (21). ${ }^{27}$ But there is something curious about it: such a logical form involves the (unexplained) deletion of the quantifier phrase everyone, which is subsequently treated as a discourse-level signal regarding which To-Do Lists to select for update-the relevant $t d l(x)$ 's, for each addressee $x$.

There is, to be clear, nothing mysterious about this sort of deletion when the deleted noun phrase is vocative-serving to explicitly indicate the addressee, but obviously not part of the relevant sentence's logical form:

(24) Bernie, take your seat

$\lambda x: x=\operatorname{Bernie}[x$ takes $x$ 's seat $]$

The fact that the quantifier phrase in (21) binds a pronoun seems, however, to indicate that it cannot be considered vocative. ${ }^{28}$

There is another option for a Portnerian analysis to try out here: leave the quantifier phrase in place, and (vacuously) $\lambda$-abstract over the entire sentence.

$$
\lambda x_{\text {addressee }}\left[\text { everyone }_{i} \text { takes }[\text { his } / \text { her/their }]_{i} \text { seat }\right]
$$

The logical form in (25), though equivalent to a proposition, is nevertheless a property, and so is fit for addition to the relevant To-Do List(s). Suppose, as seems forced, that this property is added to each (relevant) $t d l(x)$, for each addressee $x$. Ordinarily, this will have the effect of making it required, of each addressee $x$, that $x$ see to it that everyone takes their seat. In other words, we have the makings of an explanation of why an imperative like (21) would tend to make true, or else be grounded in the truth of, a modal statement like (26).

(26) Everyone [should/must] see to it that everyone ${ }_{i}$ takes $[\text { his/her/their }]_{i}$ seat

The difficulty is that imperative (21) simply lacks the envisioned connection to modal statement (26). (21) tends to make true, or else be grounded in the truth of, a modal statement like (22). (22) describes an individual-level obligation concerning each person's position relative to their own chair. It does not describe a "state-level" obligation, as (26) seems to do, regarding each person's obligation to bring about a world that is preferred from the standpoint of the speaker-a world in which everyone takes their seat. ${ }^{29}$

A final option is the introduction of a To-Do List indexed to a collective addressee-roughly, the To-Do List for everyone.

(27) $\lambda x: x=$ everyone $[x$ takes $x$ 's seat $]$

27. Though it does face the problem, mentioned in the previous section, that the mere presence of a property on a To-Do List is consistent with that To-Do List being indifferent between its agent taking a seat or not; see note 22 .

28. See earlier discussion in Mauck et al. (2005); Charlow (2010). Second-person pronouns are, for some speakers, preferred to third-person pronouns in examples like (21). So it is worth noting that there is strong reason to regard treat second-person pronouns as being anaphorically bound in such examples (Mauck et al. 2005).

29. Compare the distinction between evaluative (state-level) and deliberative (individual-level) readings of prioritizing modals advocated in Schroeder (2011). 
This is not necessarily ad hoc: collective addressees are required for understanding imperative utterances that target group actions (Charlow 2010: 231).

Play Beethoven's Fifth

$\lambda x: x=$ the orchestra $[x$ plays Beethoven's Fifth $]$

A group action is, however, clearly not the target of (21), any more than it is the target of (22). (In any case, while there is such a thing as the playing of Beethoven's Fifth by the orchestra, there is no such thing as everyone's seat, and so there can be no action that involves the taking of it by everyone.) As with conditional imperatives, the prospects for explaining the discourse role of quantified imperatives in a Portnerian clause-type analysis are unclear.

\section{Kaufmann}

Our discussion of Portner has highlighted the following three features of imperatives:

- The tight discourse-level links-of somewhat indeterminate shape-between imperatives and corresponding modal statements

- The information-sensitivity of imperatives (witnessed in conditional imperatives)

- The ability of quantifier phrases to take non-vacuous "scope" over imperative "force"

Impressively, there is an account of imperatives that would seem to get all of these features for free: the modal account, championed most comprehensively by Magdalena Kaufmann.

\subsection{Imperatives as Performative Modals}

Kaufmann (see Schwager 2007; Kaufmann \& Schwager 2011; Kaufmann 2012) analyzes imperative statements as modal statements. There are two theses to distinguish here: one about the compositional semantics of imperatives-which Kaufmann supports with a wide range of linguistic data—another about their conventionally proffered contents.

\section{Imperatives Contain Modal Quantifiers}

Imperatives contain prioritizing necessity modals in their compositional semantics

\section{Imperatives Express Modal Propositions}

The conventionally proffered content of an imperative is a modal proposition

Since my interest here is confined to clause-type analysis of the imperative, I will here confine my attention to the second of these theses (recall $\S 2.3$ ). ${ }^{30}$

The notion that Imperatives Express Modal Propositions invites an incredulous stare (as Kaufmann appreciates). The behavior of imperatives in discourse is altogether distinct from that of declaratives; indeed, this one of the insights around which clause-type analysis is built. Imperative utterances strikingly resist characterization as true or false-indeed, attempts at such

30. von Fintel \& Iatridou (2009, forthcoming) adduce interesting data from Imperative-and-Declarative (IaD) constructions (constructions like drink another beer and you'll lose your lunch) that seems to suggest that (i) imperatives do not contain prioritizing necessity modals in their compositional semantics; (ii) such constructions are best thought of under the rubric of conditional conjunction ( $\approx$ if you drink another beer, you'll lose your lunch) (cf. Culicover \& Jackendoff 1997; Klinedinst \& Rothschild 2012); (iii) for such constructions to function as conditional conjunctions, imperatives must have the sort of "minimal" compositional semantics suggested by Portner. I am inclined to agree with them, at least in part, but nothing here will turn on this, as I will explain. 
characterization are, in every case of which I am aware, ungrammatical-and, relatedly, seem not to warrant the sorts of downstream discourse moves we normally take assertions to warrantaffirmation (on grounds of truth), rejection (on grounds of falsity), and so on. ${ }^{31}$ In other words, imperative utterances, quite unlike modal utterances, cannot be used to report or state standing modal facts. This is quite surprising, if the conventionally proffered content of an imperative is in fact a modal proposition.

The insight on which Kaufmann builds her account is that the striking differences between imperatives and modal declaratives might be accounted for by appeal to the alleged performativity of imperative utterances. Imperative utterances, Kaufmann suggests, are performative in exactly the way that performative uses of their corresponding modals are performative. Like imperatives, performative utterances lack a reportative or descriptive function.

(29) A: I promise to be at your party B: \#No you don't/\#That's false!

(30) Louis XIV decrees: You may not execute this peasant! Executioner: \#Yes, I may

Thus, if imperative utterances are a species of (obligatorily) performative modal utterances, we can straightforwardly explain why imperatives cannot be used to report standing modal facts (and hence, for example, cannot be targeted by the sorts of downstream discourse moves that such reports tend to warrant).

What feature might make imperative utterances obligatorily performative and thus "shield the truth value [of an imperative] from being conversationally accessible" (Kaufmann 2012: 57)? Example (30) is suggestive here. A performative interpretation of a modal utterance is forced in a context in which it is generally known that the modal facts are at the discretion, or under the authority, of the speaker. The basic idea here is due to another target of the incredulous stare:

There is a certain symbol! that may be prefixed to any sentence $\phi$ to make a new sentence ! $\phi$, called an imperative sentence, that is true at $t$ at $w$ iff $\phi$ is true at $t$ at every world that is both accessible and permissible at $t$ at $w \ldots$ The [imperative] may be used to command: the Master says it to the Slave, his purpose is to control the Slave's actions by changing the sphere of permissibility, and truthfulness is automatic because the sphere adjusts so that saying so makes it so. (Lewis 1979: 164-6, my emphasis)

A pressing question is whether actual conversationds share the features of Lewis' "little language game"? Plausibly, they do, provided that we understand the flavor of modality expressed by the imperative in a sufficiently subtle manner-something like in view of what the speaker says is X-necessary, where $X$ may be any of the familiar flavors of modality: deontic, legal, bouletic, teleological, and so forth (see esp. Kaufmann 2012: Ch. 4). Command uses of imperatives are associated with an in view of what the speaker says she commands-flavor, suggestion uses with an in view of what the speaker says is necessary for the addressee to fulfill her desires-flavor, and so on. While Portner achieves variability in illocutionary force by appeal to differences in which To-Do Lists are targeted for update by an imperative utterance, Kaufmann achieves variability in illocutionary force by appeal to differences in which flavor of modality is expressed by the imperative utterance's modal logical form. ${ }^{32}$

31. Additionally, imperatives, as we have already seen, resist embedding in environments that ordinarily take propositional arguments: indicative antecedents, as the complements of propositional attitude verbs, etc. I here focus on Kaufmann's attempt to account for the diverse behavior of imperatives and modal declaratives in discourse. Differences in embeddability are plausibly due to the distinctive syntax of the imperative.

32. I have reservations regarding Kaufmann's use of authority to achieve performative force, which she implements via what she terms an Epistemic Authority Presupposition. This presupposition roughly enforces the speaker's infalli- 


\subsection{Explanations}

A modal account seems immediately well-positioned to explain the links in discourse between imperatives and corresponding modal statements. These are, on my understanding of Kaufmann's account, akin to the links between the following two statements of deontic necessity:

(31) [Given what I say is $X$-necessary] you [should/must] shut the door

(32) [Given what is $X$-necessary] you [should/must] shut the door

These links might appear initially mysterious-what do the addressee's actual obligations (given $X$ ) have to do with what the speaker says is necessary (given $X$ )? Kaufmann suggests that the gap here is filled by the following principle, connecting sentences of the imperative clause-type to affirmative speech acts: 33

\section{Ordering Source Affirmation}

The speaker of an imperative utterance affirms the ordering source that determines the flavor of modality expressed by the imperative as the correct ordering source to use in practical deliberation for the addressee.

Suppose (32) expresses the verdict of an episode of practical deliberation, concerning what to do relative to a decision problem that is salient in the context of utterance (Kaufmann 2012: 162). The speaker's affirmation of the ordering source for her own imperative utterance as the ordering source to consult in deliberation about what to do in the salient decision problem-if accepted at the context-will reliably explain the truth of (32) in a context in which the imperative utterance has been made. (If the affirmation is rejected, the suggested connection will fail, but this is just what we would expect-a rejected imperative has no reliable effect on the truth of a corresponding deontic modal.)

On information-sensitivity and quantification, we can be very brief. Modals are the paradigmatic information-sensitive expression; if imperatives are modals, the information-sensitivity attested in conditional imperatives follows directly. On quantification, any good theory of natural language modality must identify a sense in which a sentence like (22) reports an individual-level obligation concerning each person's position relative to their own chair. Once such a theory is in hand, a theory of how a quantified imperative like (21) tends to generate this sort of individuallevel obligation would seem to be close behind.

\subsection{Criticisms}

This section briefly advances two criticisms of Kaufmann's approach, both of which I take to stem from her account's more or less orthodox understanding of the shape of clause-type theorizing. The first criticism is that, perhaps contrary to appearances, Kaufmann, like Portner, lacks any clear explanation of the canonical discourse role of quantified imperatives like (21), repeated here as (33):

(33) Everyone ${ }_{i}$ take $[\text { his/her/their }]_{i}$ seat

bility with respect to the truth of the modal proposition expressed by the imperative (Kaufmann 2012: Ch. 4). The conceptual and explanatory role of Epistemic Authority is difficult to understand in Kaufmann's analysis (for skeptical discussions, see Charlow 2010, 2011). I pass over it here.

33. This principle receives various formulations in Schwager (2007); Kaufmann \& Schwager (2011); Kaufmann (2012). The formulation here aims to capture the common thread between them. One might worry that this principle is stipulated to make the account work. Kaufmann argues (see, e.g., Schwager 2007: note 13) that the principle is independently motivated by the badness of sequences like \#go to Kyoto, although I don't think you should. 
From the discussion of Portner's difficulties with quantified imperatives (\$3.4), it is already fairly clear that the relationship between (i) the ordering source constructed to verify the truth of the performatively used imperative modal, (ii) the ordering source used in the interpretation of descriptions of addressee-obligations like (22), repeated here as (34), is not as transparent as the Ordering Source Affirmation principle would seem to suggest.

(34) Everyone $_{i}[$ should/must $]$ take $[\text { his/her/their }]_{i}$ seat

The most plausible representation of the ordering source for (33) contains the proposition that everyone takes his/her/their seat (or else a collection of propositions that together entail this one). But if this is the ordering source affirmed by the speaker for use in practical deliberation by the imperative's addressees, Kaufmann apparently predicts a relationship, not between (33) and the modal statement in (34), but rather between (33) and the modal statement in (26), repeated here as (35):

(35) Everyone [should/must] see to it that everyone ${ }_{i}$ takes $[\text { his/her/their }]_{i}$ seat

This is, I have already argued, the wrong relationship to predict. Kaufmann's coarse-grained Ordering Source Affirmation principle, like Portner's suggested coarse-grained link between imperatives and To-Do Lists, apparently gets the wrong proposition into the ordering source(s) relevant for the evaluation of the corresponding modal declarative.

This sort of worry might be somehow finessed. My other worry is more serious. Kaufmann endeavors to explain the factors that might "shield the truth value [of an imperative] from being conversationally accessible" (my emphasis). Even if this explanation succeeded-I have here argued that it does not-it would not explain why the modal proposition expressed, on her account, by an imperative would be, as it clearly is, inaccessible to propositional cognition, i.e., cognitive . Even if Kaufmann has explained why imperative utterances resist characterization as true or false in discourse, she has yet to explain why, roughly speaking, imperative thoughts resist characterization as true or false/likely or unlikely/desirable or undesirable, and so on. ${ }^{34}$

Somewhat less roughly, according to the account of canonical cognitive roles sketched in \$2.4, canonical cognitive roles for sentences are related to their canonical discourse roles, via their conventionally proffered contents. According to Kaufmann, the conventionally proffered content of an imperative is a modal proposition. When that proposition is tokened in discourse using an imperative, the utterance is assigned a performative interpretation. But when that same proposition is tokened in thought with an imperative, it is hard to know what to say. While performativity might explain why the modal proposition expressed, by Kaufmann's lights, by the imperative is conversationally inaccessible, the notion of performativity has no clear purchase when theorizing about an agent's cognitive system: performativity seems unable to explain why the modal proposition expressed, by Kaufmann's lights, by the an imperative is inaccessible to cognitive environments that select for inputs of propositional type. Provisionally, then, we may conclude that Kaufmann's account fails to account for the following facts (and manifold others):

- Probability functions are undefined for imperatives.

- An agent cannot have a desire whose content is imperative.

Here is a possible line of reply. As we have observed, attitude-ascriptions embedding imperatives are ungrammatical; thus, it might be suggested that the reason agents cannot have desires with imperative contents is that there are no grammatical sentences reporting such attitudes. In

34. Compare the critique of Kratzer's stipulation that probability judgments cannot be directed to the proposition expressed by a conditional (see, e.g., Kratzer 2012: 107) pursued by Rothschild (2012: 54) and Charlow (2016b). 
reply: the nonexistence of a grammatical way of reporting a state of affairs $S$ has basically no bearing on whether $S$ is possible. The theorist has (and ought to have) complete freedom to define a metalanguage unencumbered by the grammatical limitations of natural language. The probability calculus, to take one obvious example, is such a metalanguage: the only restriction on applying a probability function $\operatorname{Pr}$ to a sentence $\phi$ is that $\phi$ 's semantic value is an element of the Boolean algebra over which $P r$ is defined. If we are resistant to the notion that an imperative could have a probability (as seems correct), we cannot countenance the notion that imperatives have proposition-type semantic values. Similar observations will hold for metalanguages that contain a truth-predicate or attitude-predicate that is stipulated to select for arguments of propositional type.

\section{Cognition First}

On the view I will outline here, tokening an imperative content in thought is a mundane occurrence. A speaker tokens such a content when forming the normative judgment that is expressed by a sincere imperative utterance, and an addressee does it when updating on the content that is expressed by such an utterance, and thereby coordinating with the speaker on the normative judgment that her utterance expressed. (A normative judgment, in the intended sense, is a particular kind of judgment-what kind of judgment, I'll say more about below-about what the addressee should or must do.) This section will sketch an analysis of imperatives that attempts to build on these (admittedly somewhat cryptic) suggestions. ${ }^{35}$

It remains true that natural languages lack a canonical form for ascribing cognitive states with imperative contents to agents. That is to say, they lack a form which embeds a clause of the appropriate type under an attitude verb. In this respect, imperatives are unlike declaratives and interrogatives; recall example (1). Nevertheless, I will argue, the suggestion that a sincere imperative utterance tends strongly ${ }^{36}$ to express a speaker's normative judgment concerning the actions of her addressees ${ }^{37}$ is both sensible and explanatory.

If this is right, the cognitive role of contents of imperative type will be accessible via attitudeascriptions that attribute normative judgments to agents. (Indeed, even if it is not right, consideration of normative attitude-ascriptions is, I will argue, a productive way to begin theorizing about the cognitive role of the imperative.) This appears, at first blush anyway, to be a plausible prediction. Consider the unremarkable (if tedious) narrative in (36).

(36) a. Bernie thinks Hillary should shut the door

b. So, Bernie plans for Hillary to shut the door

c. So, Bernie tells Hillary to shut the door

d. Hillary accepts Bernie's utterance

e. So, Hillary comes to think that she should shut the door

f. So, Hillary plans to shut the door

35. The view I defend here descends from Charlow (2011, 2014a) (which also offer a fuller defense of the view than I am able to undertake here). I take Condoravdi \& Lauer (2012); Harris (2014); Starr (forthcoming) to be in agreement on much of what I say in this final section. Harris, in particular, describes an cognitive approach to semantic and pragmatic theorizing (generally, but also specifically for imperatives) that has many affinities with the view I lay out here. My own view has been influenced in many ways by their work (and, more recently, by Roberts (2015)). A full comparison is, alas, beyond the purview of this paper.

36. The tendency is imperfect, as can be seen from, e.g., well-wish imperatives like (7). More on this below.

37. Probably within a salient decision problem. Kaufmann, we noted, makes use of the notion of a decision problem in her unpacking of the Ordering Source Affirmation principle. I have argued elsewhere for the representation of decision problems (as well as decision theories) in the semantics of prioritizing deliberative modals (see, e.g., Charlow 2016a, forthcoming). 
As this narrative illustrates, normative judgment-of the sort routinely attributed by sentences like (36a) and (36e) - is plausibly implicated in both the production of a paradigmatic imperative utterance, as well as its perlocutionary force. I stress that I am not assuming that this holds true of all paradigmatic imperative utterances. I do assume that this is a useful point from which to begin theorizing. Let us see where it takes us.

\subsection{Internal and External Attitudes}

If normative judgment, of the sort attributed by (36a) and (36e), were simply a propositional attitude, the suggestion to treat such normative judgments as a guide in theorizing about the semantics of imperatives would get us nowhere fast. Very plausibly, however, normative judgment is not univocally propositional. As others have noticed, it is possible to read (36a) in both what I will call internal and external senses. ${ }^{38}$ The external reading of (36a) attributes to Bernie belief in a propositional content representing the proposition that Hillary shuts the door as required relative to a salient body of law, preference, regulation, etc. (The propositional complement, in the case of the external reading of ( $36 \mathrm{a})$, is analogous to the above-mentioned "reportative" reading of the prioritizing modal.) The internal reading of (36a), however, attributes to Bernie roughly the possession of a plan ${ }^{39}$ according to which it is required that Hillary shut the door. I will take it as obvious that the state of having a plan that requires $x$ and the state of believing that $x$ is required, relative to a salient body of law, preference, regulation, etc., are distinct.

How could these two readings of normative judgment-ascriptions exist? How are these two readings related? Here is one possibility, which would explain both the existence of these readings, as well as the systematic semantic relationship that seems to hold between them:

\section{Imperatives Characterize Modal Propositions}

Imperative contents are functions mapping some kind of argument into a modal truth condition.

The suggestion, in other words, is to think of (metalinguistic representations of) imperative contents as derived from (metalinguistic representations of) modal propositions through some ordinary compositional mechanism, like $\lambda$-abstraction (Heim \& Kratzer 1998).

As illustration, consider the following (extensional) representation of a modal logical form:

$$
\square_{f, g}(\text { Restrictor })(\text { Scope })
$$

This representation follows Kratzer (1981): modals are generalized quantifiers expressing a relation between (i) a domain of quantification jointly characterized by the Modal Base $f$, the Ordering Source $g$, and a (explicitly or implicitly provided) Restrictor, and (ii) a set of possibilities characterized by the Scope. Provided we assume that there are finitely many worlds compatible with $f$, the domain of quantification is simply the set of possibilities compatible with $f$ and the Restrictor that are minimal in the ordering characterized by $g$. The relationship expressed between this domain and the set of possibilities characterized by the modal's Scope is simply $\subseteq$.

A logical form of this shape is tailor-made to account for external (reportative) readings of modal expressions. Such a logical form expresses the proposition that all possibilities in the domain of quantification (jointly characterized by $f, g$, and the Restrictor) witness the truth

38. This is an old, if disputed, observation in the meta-ethical literature on judgment internalism. The Expressivist Allan Gibbard has developed a "plan-laden" semantics for normative attitude-ascriptions around it (see esp. Gibbard 1990, 2003). For more recent discussion, see Charlow (2015); Cariani (2016); Yalcin (forthcoming).

39. Or preference, or desire, or whatever (though I will generally default to 'plan'). 
of the Scopal proposition. If an agent stands in a cognitive relationship to this logical forme.g., belief-then we may say that the agent believes that the Scopal proposition is required by the domain of quantification jointly characterized by $f$, $g$, and the Restrictor.

A logical form of closely related shape is, I suggest, tailor-made to account for internal readings of modal expressions:

$$
\lambda g\left[\square_{f, g}(\text { Restrictor })(\text { Scope })\right]
$$

Such a logical form expresses the property an ordering source $g$ has iff the Scopal proposition is required by the domain of quantification jointly characterized by $f, g$, and the Restrictor. As a convenient shorthand, we may say that this is the property $g$ has when $g$ requires the Scopal proposition (relative to the relevant Modal Base and Restrictor). Obviously this is not a truth condition: it is a (modally specified) property of the ordering source. Thus, unlike Kaufmann's account, our account is at no risk of misconstruing the canonical cognitive role of imperative contents as akin to the canonical cognitive roles of propositions. ${ }^{40}$

There is no antecedent reason to think that an agent could not stand in a cognitive relationship to this sort of logical form. If, for example, an agent's plans are representable with $g$, then we may say that the agent cognitively instantiates the property expressed by this logical form. ${ }^{41}$ My present suggestion is that we may refer to the adverted sort of cognitive relationship as a belief-and, more specifically, as an internal normative judgment).

The overarching suggestions of this section have been these.

- External readings of normative judgment-ascriptions ascribe a relationship between an agent and a propositional content.

- Internal readings of normative judgment-ascriptions ascribe a relationship between an agent and an imperative content.

- Imperative contents characterize properties of the semantic parameter responsible for the action-guiding/normative flavor of prioritizing modalities-the ordering source.

- The propositional content that is the object of an external normative judgment-ascription is related to the imperative content that is the object of an internal normative judgmentascription by $\lambda$-abstraction.

I will not argue in any great detail for these suggestions here-though I will try to outline many of their explanatory attractions. It is, for instance, worth noting that these suggestions together paint a distinctive (and, so far as I see, quite plausible) picture of narrative (36): (36a) (on its internal reading) and (36b) ascribe a relationship between Bernie and an imperative content

40. What of the earlier-mentioned criticisms of Kaufmann's account that target the claim that the compositional semantics of an imperative is modal (e.g., von Fintel \& Iatridou 2009, forthcoming)? Such criticisms do not apply to the account I have given-I stress that I have not given a compositional semantics for the imperative. Which is to say: I have not, in this paper, given any account of what an imperative contributes to an environment like the following.

(37) Drink another beer, and you'll lose your lunch

(38) Stop drinking beer, or you're grounded

These sorts of "Imperative-and/or-Declarative" constructions are, in my view, probably just equivalent to ordinary conditionals (cf. Culicover \& Jackendoff 1997; Klinedinst \& Rothschild 2012). I do not see the proposal I have suggested here as contributing to the analysis of such constructions as conditional in meaning. For all I have said here, the compositional semantic contribution of an embedded imperative is exhausted by what I have called the Scopal proposition-in the case of shut the door, Hillary, the proposition that Hillary shuts the door-and the conventionally proffered content of an imperative is derived from the Scopal proposition at a distinct level of semantic representation.

41. I provide an account of the relationship between a formal semantic object constructed out of possibilia (like an ordering) and the actual plans or preferences of an agent in Charlow (2015: §5). Neither that account nor the account presented here is intended as a compositional semantics for belief-ascriptions. Since, however, they are intended as accounts of the truth conditions of internal and external readings of belief-ascriptions, they should be compositionally implementable. I see no reason to think they would not be. 
(which Bernie instantiates just if he has a plan representable with an ordering source satisfying the property characterized by this imperative content). Bernie tokens this content in discourse when he utters the imperative shut the door, Hillary. In accepting Bernie's utterance, Hillary comes to bear a cognitive relationship to this same imperative content. As with Bernie, this amounts to her adopting a plan that is representable as an ordering source satisfying the property characterized by this imperative content.

\subsection{Embeddings}

This section will extend the foregoing analysis to the two embeddings of imperatives that have featured in this paper: conditional and quantified imperatives. Let us again begin by considering normative judgment-ascriptions:

(39) Bernie thinks Hillary should shut the door if it starts to rain

(40) Bernie thinks everyone ${ }_{i}$ should take $[\text { his/her/their }]_{i}$ seat

On its internal reading, I suggest that (39) asserts a cognitive relation-here termed Bel-between Bernie and an imperative content:

$$
\operatorname{Bel}\left(\text { Bernie, } \lambda g\left[\square_{f, g}(\text { it starts to rain)(Hillary shuts the door) }]\right)\right.
$$

If imperatives conventionally proffer the property an ordering source has when it requires the Scopal proposition, conditional imperatives conventionally proffer the property an ordering source has when it requires the Scopal proposition, against a restriction to possibilities compatible with their antecedents. Indicative antecedents play an ordinary compositional restrictive function-albeit at the level of conventionally proffered content. ${ }^{42}$ I note in passing that, so long as the ordering characterized by $g$ depends on the information expressed by the restrictor clause, this account is well-positioned to account for the information-sensitivity outlined in $\$ 3.3 .{ }^{43}$

On its internal reading, I suggest that (40) asserts the Bel-relation, not between Bernie and a single imperative content, rather between Bernie and a constellation of imperative contents: ${ }^{44}$

$$
\forall x: \operatorname{Bel}\left(\text { Bernie, } \lambda g\left[\square_{f, g}(\top)(x \text { takes } x \text { 's seat })\right]\right)
$$

Universal quantifiers play an ordinary quantificational function when they take scope over the imperative - when, roughly speaking, they take scope over an imperative force operator in the metalanguage. (When they do so, their semantic function is analogous to conjunction of substitution instances.) If, then, imperatives conventionally proffer the property an ordering source has when it requires the Scopal proposition, universally quantified imperatives conventionally proffer a constellation of properties: for each addressee $x$, the property an ordering source has

42. I am not a proponent of Kratzer's restrictor analysis of the conditional (see Charlow 2016b), but explaining why (and how to modify the account to deal with this) would take me too far afield. I will note that I-like most other folks of the "dynamic" persuasion-think of indicative antecedents (as well as quantifier phrases) as, roughly speaking, devices for expressing context change or discourse operations. From this perspective, the notion that indicative antecedents (and quantifier phrases) play their main semantic role at the level of conventionally proffered content (and that quantifier phrases can nevertheless bind downstream pronouns) is expected. A useful formalism for modeling this level of semantic representation is Segmented Discourse Representation Theory (see especially Asher \& Lascarides 2003).

43. For varying accounts of this dependence-which goes by the name of "serious informational dependence" in the literature-see Kolodny \& MacFarlane (2010); Charlow (2013b); Cariani et al. (2013); Carr (2015).

44. Since the imperative in question is unconditional, its logical form is vacuously restricted, to $T$. A more realistic analysis, pursued in Charlow (2011: Ch. 4), would treat the modal's restriction as jointly determined by (i) a variable tracking contextually imposed restrictions, (ii) explicitly introduced restrictions (if the imperative is conditional). On the character of modal subordination for imperatives, see Charlow (2011: 184ff). 
when it requires $x$ to realize the Scopal proposition. And this is exactly the sort of story for quantified imperatives I have suggested is needed.

\subsection{Illocution via Cognition}

Imperative utterances, on the proposal I have outlined here, conventionally proffer the contents of (internal readings of) normative judgment-ascriptions. Trivially, they proffer these contents for acceptance. But how do addressees (or contexts) that accept an imperative utterance update on an imperative content? I have been speaking in a rough-and-ready way about this issue above. In this section, I will try to be more precise.

First, a necessary formal refinement. Following Portner, we index ordering sources to agents (to, inter alia, make room for the intuition that the considerations that bear on a judgment of what an agent $x$ should do-the ordering source relevant for evaluating a modal judgment of this form-can vary with $x$ ). The conventionally proffered content of an ordinary imperative can thus be represented by the following schematic logical form:

$$
\lambda x \lambda g\left[\square_{f, g(x)}(\text { Restrictor })(\text { Scope })\right]
$$

This function's individual argument may be associated with a definite individual, provided either implicitly (e.g., demonstratively) or explicitly (in the case of an explicit addressee imperative like if it starts to rain, shut the door, Hillary).

$$
\lambda g\left[\square_{f, g(\text { Hillary) }} \text { (it starts to rain)(Hillary shuts the door) }\right]
$$

Or the variable can be bound by the universal quantifier, in which case we arrive at the following constellation of contents:

$$
\bigcup_{x}\left\{\lambda g\left[\square_{f, g(x)}(\text { Restrictor })(\text { Scope })\right]\right\}
$$

This is the constellation of contents that results from collating each content of the form $\lambda g\left[\square_{f, g(x)}(\right.$ Restrictor $)$ (Scope) $]$ (for each addressee $x$ in the quantifier's domain).

This refinement in place, we are in a position to state a schematic recipe for determining how, given an imperative utterance that is accepted, both addressees and contexts update on the content of that utterance. Step One is a formal assignment of imperative contents.

\section{Step One: Semantics for Imperatives}

The imperative interpretation function $\|\cdot\|$ is a function mapping imperatives to their contents, where:

$$
\begin{aligned}
\|(\text { if } X)(a ! Y) \| & =\left\{\lambda g\left[\square_{f, g(a)}(X)(Y)\right]\right\} \\
\| \forall x(\text { if } X)(x ! Y) \| & =\bigcup_{x}\left\{\lambda g\left[\square_{f, g(x)}(X)(Y)\right]\right\}
\end{aligned}
$$

Of note: (i) I treat all imperative contents as sets of properties of ordering sources. (In the case of unquantified imperatives, this set is a singleton.) (ii) I represent a contextually disambiguated imperative of the form see to it that $X, a$ with the abbreviation $a$ !X. (iii) An ordinary imperative is treated as a conditional imperative with a restriction to $T .45$

45. This is not intended as a final or complete statement of the view. It ignores context-sensitivity (and plays fastand-loose with use and mention in, e.g., its handling of variables), for one. For two, it does not account for existential 
Step Two: we state a principle linking imperative contents to illocutionary forces or discourse moves. Because imperative contents are, in a manner of speaking, properties that can be instantiated by psychological concreta (e.g., an agent's plans), the force of an imperative $\Phi_{\text {IMP }}$ is, very simply, to propose that a range of selected states come to "believe" (in the internal sense) $\left\|\Phi_{\text {IMP }}\right\| . .^{46}$ If $\left\|\Phi_{\text {IMP }}\right\|$ contains a property of the ordering source for agent $x$-a property of the form $\lambda g\left[\square_{f, g(x)}(X)(Y)\right]$ - the imperative proposes that the state that $g(x)$ represents come to "believe" (in the internal sense) $\lambda g\left[\square_{f, g(x)}(X)(Y)\right]$.

\section{Step Two: Force Assignment for Imperatives}

Consider an utterance of the imperative $\Phi_{\mathrm{IMP}}$, where:

$$
\left\|\Phi_{\text {IMP }}\right\|=\left\{\lambda g\left[\square_{f, g\left(x_{1}\right)}(X)(Y)\right], \ldots, \lambda g\left[\square_{f, g\left(x_{n}\right)}(X)(Y)\right]\right\}
$$

The force of $\Phi_{\mathrm{IMP}}$ is to propose that the salient ordering source for $x_{i}$ satisfy $\lambda g\left[\square_{f, g\left(x_{i}\right)}(X)(Y)\right]$ (for each $i$ ).

There is a risk this formalism will obscure the simple thought that underlies it: an imperative utterance, directed at a single addressee $x$, proposes that $x$ 's plans (equally, the context's representation of $x$ 's plans) come to be representable with an ordering source that requires the imperative's prejacent. This follows from the fact that, if $g(x)$ is the salient ordering source for $x$, and $g(x)$ gives a set of things $x$ plans on, then changing the value of $g(x)$ so that it comes to satisfy the specified modal property must involve a corresponding change in $x$ 's plans. An imperative utterance, directed at multiple addressees $x_{1}, \ldots, x_{n}$, proposes, for each $i$, that $x_{i}$ 's plans (equally, the context's representation of $x_{i}$ 's plans) come to be representable with an ordering source that requires the imperative's prejacent. In a slogan: imperative utterances are conventionally associated with attempts to get their addressees to plan on realizing their prejacents. In an even briefer slogan: imperatives conventionally express directive speech acts.

How might the manifold illocutionary forces associated with standard imperative utterances be accounted for on this proposal? Here I must be brief (while pointing my reader to earlier work). Speaking broadly, command, suggestion, invitation, etc., interpretations will be construed as determinates of the determinable DiRective. Since an agent's plans (and the ordering sources that represent her plans) come in many varieties-plans for pursuing what duty requires, plans for pursuing what her desires require, and so on-and are, additionally, represented in various loci-by the agent, by the context, and by agents distinct from the agent-this account's degree of illocutionary flexibility compares favorably with the degree of illocutionary flexibility one finds in both Portner's account: so far as I can see, all the maneuvers that Portner exploits to account for illocutionary variability are open to the account stated here. A suggestion or invitation, for instance, may be construed as a proposed update to what an addressee plans for the sake of pursuing her own desires. A command may be construed as a proposed update to what an addressee plans for the sake of doing her duty (or perhaps to what an addressee plans sans phrase). And so on. ${ }^{47}$

quantification that takes scope over imperative "force". On existential quantification see Charlow (2011: 155ff).

46. The range of states to which such an update is proposed may include the context. "Belief" by a context is analogous to presupposition: a context $c$ believes that $p$ iff $p$ is presupposed at $c$. On the account suggested here, if a speaker attempts to update the context with an imperative-I stress that I take no stand on whether speakers should generally be understood as attempting to do such a thing-the speaker makes a discourse move whose intended effect is to make an internal normative judgment presupposed.

47. For further details, including how to derive non-directive (permission, instruction) interpretations of imperatives under the rubric of indirect speech acts (cf. §2.1), see Charlow (2011: Ch. 3). A brief summary: permission interpretations are supplied by abduction in contexts where a directive interpretation cannot be attributed to a rational speaker. Instruction interpretations (e.g., 'to get to Union Square, walk along 14th') are generated by combining 


\subsection{Extensions}

If imperatives are linked to canonical discourse/cognitive roles by the Force Assignment principle, how are declaratives and interrogatives linked to canonical discourse/cognitive roles? Supposing we are in fact after a unified account here, my suggestion here will be simple and fairly conservative. The standard proffered contents of both declaratives and interrogatives-propositions and questions, respectively-provide recipes for characterizing the cognitive properties one instantiates when one accepts a declarative and accepts an interrogative (in the special sense of §2.4). The Force Assignment principle may be extended to these properties, and the canonical discourse roles of declaratives and interrogatives subsumed within it. ${ }^{48}$

A proposition-to fix ideas, let this be a set of possible worlds-determines the property of self-locating in one of those possible worlds. A question-to fix ideas, let this be a way of partitioning a set of possible worlds-determines the property of partitioning the set of worlds in which one self-locates along the lines of that partition. A declarative that expresses a proposition $p$ proposes that a salient representation of location in modal space represent the location as falling within $p$. An interrogative that expresses a partition $\{p, \bar{p}\}$ proposes that a salient representation of issues-under-discussion come to partition its information into $p$-regions and $\bar{p}$-regions.

I pitch this as a "conservative" way of extending Force Assignment to cover the other major clause types. That said, notice that if the interpretation function $\|\cdot\|$ maps sentences into their conventionally proffered contents, the conventionally proffered contents of declaratives and interrogatives, like those of imperatives, are just characteristics of abstract entities representing, in the first instance, a cognitive state of an agent. Semantic theorizing, at this level anyway, is cognitively loaded in a way that may be startling to some practitioners. Startling or not, the analysis underlying this understanding should be given the chance to earn its linguistic keep.

\section{Conclusion}

This paper developed a clause-type analysis of the imperative that improved, I argued, on the major extant clause-type analyses of the imperative: the Dynamic Pragmatic account of Portner, and the Modal account of Kaufmann.

Portner's analysis typed clauses in virtue of the semantic types of their proffered contents, and assigned them a particular force - addition of a proffered content to a set (or sets) of objects of the same semantic type-in virtue of this type. This analysis ran into difficulty with conditional and quantified imperatives, both of which seem to lack proffered contents of the sort that would allow conditional and quantified imperatives to play the sort of role in discourse that they seem, in fact, to play. Portner's understanding of clause-type theorizing-an understanding which compels him to identify proffered contents for conditional and quantified imperatives of a type fit for addition to a To-Do List-limited his options for dealing with these difficulties.

Seen from the vantage of this (admittedly focused) range of explananda, Kaufmann's analysis appeared to represent an improvement over Portner's. By introducing modality into the analysis of the imperative-via the suggestions that imperatives (i) contain modal quantifiers in their compositional semantics and (ii) conventionally proffer modal propositions when uttered

an imperative content-a function from an ordering source into a modal proposition-with an ordering source (expressing the designated goal-in this case, getting to Union Square) by a version of Functional Application. The instruction imperative is thus interpreted as proffering a modal content: that the addressee should/must perform the relevant action (walking along 14th) in order to achieve the designated goal (getting to Union Square).

48. For approaches to semantic and pragmatic theorizing that are broadly in this vein (though developed specifically in the context of a nonpropositional semantics and pragmatics of epistemic and probabilistic operators in declarative sentences), see Swanson (2006, forthcoming); Yalcin (2011, 2012a); Rothschild (2012); Moss (2015). An important question that I do not address here is how to fit declaratives that express cognitive properties that are not equivalent to propositional belief (e.g. epistemic and normative uses of modals) into the broader project of clause-type theorizing. 
in discourse-Kaufmann was able to exploit the flexibility of modal expressions, with respect to their information-sensitivity, their ability to take scope under quantificational operators, and their ability to receive performative interpretations. This last ability, impressively, rendered the imperative's alleged propositional content inaccessible in discourse and seemed to offer an appealing account of the discourse role of imperatives of basically any type.

The utility of modal performativity was, however, limited. Clause-type analysis aspires to offer a theory of proffered content. One therefore expects a clause-type analysis to explain the sorts of changes in both common and individual attitudes that result when the proffered content of an imperative is tokened in thought (for, e.g., the sake of being updated on). A propositional analysis of the imperative could not explain why, for example, an imperative could not be entertained as likely, true, or desirable.

A common feature of these accounts was their attempt to exploit coarse-grained discourse principles-Portner's Force Assignment, Kaufmann's Ordering Source Affirmation-connecting utterances of typed clauses to (para-)illocutionary forces-To-Do List addition, for Portner, and affirmation of the ordering source, for Kaufmann. In both cases, any connection of an imperative to the truth of a corresponding modal sentence was indirect or derived-resulting from the application of the relevant discourse principle to the utterance's claimed proffered content.

On the "Cognition First" account advanced in this paper, the connection between imperatives and corresponding modal sentences was not indirect in this fashion. On this account, the content of an imperative may be simply read off the content of a corresponding normative judgment-ascription (on what I called its internal reading). An utterance proffering this content in discourse is associated with a very natural discourse role: a proposal, roughly, that an addressee $x$ come to share the speaker's view of what $x$ should do.

Like Kaufmann's account, my account exploited the scope-taking abilities and informationsensitivity of modal expressions in accounting for quantified and conditional imperatives. Unlike Kaufmann's account, I required neither that modal expressions figure in the compositional semantics of imperatives, nor that imperatives proffer modal propositional contents that are, quite exceptionally, inaccessible in conversation or cognition. An imperative, on my analysis, expresses a characteristic of a plan (by expressing a characteristic of an ordering source). Such characteristics are not evaluable for truth, in conversation or cognition. To adopt such a characteristic is to come to have a certain kind of plan, not to commit oneself to representing the world in any sort of fashion.

\section{References}

Aloni, Maria. 2007. Free choice, modals, and imperatives. Natural Language Semantics 15: 65-94. doi:10.1007/s11050-007-9010-2.

Åqvist, Lennart. 1964. Interpretations of deontic logic. Mind 73: 246-253. doi:10.1093/mind/LXXIII.290.246.

Asher, Nicholas \& Alex Lascarides. 2001. Indirect speech acts. Synthese 128: 183-228. doi:10.1023/A:1010340508140. Asher, Nicholas \& Alex Lascarides. 2003. Logics of Conversation. Cambridge: Cambridge University Press.

Austin, J. L. 1975. How to Do Things with Words. Cambridge: Harvard University Press.

Bhatt, Rajesh \& Roumyana Pancheva. 2006. Conditionals. In M. Everaert \& H. van Riemsdijk (eds.) The Blackwell Companion to Syntax, vol. 1, 638-687. Malden: Blackwell.

Cariani, Fabrizio. 2016. Deontic modals and probabilities: One theory to rule them all? In N. Charlow \& M. Chrisman (eds.) Deontic Modality. Oxford University Press.

Cariani, Fabrizio, Magdalena Kaufmann \& Stefan Kaufmann. 2013. Deliberative modality under epistemic uncertainty. Linguistics and Philosophy 36: 225-259. doi:10.1007/s10988-013-9134-4.

Carr, Jennifer. 2015. Subjective Ought. Ergo 2: 678-710. doi:10.3998/ergo.12405314.0002.027.

Charlow, Nate. 2010. Restricting and embedding imperatives. In M. Aloni, H. Bastiaanse, T. de Jager \& K. Schulz (eds.) Logic, Language, and Meaning: Selected Papers from the 17th Amsterdam Colloquium. ILLC. doi:10.1007/9783-642-14287-1_23.

Charlow, Nate. 2011. Practical language: Its meaning and use. http://www.natecharlow.com/work/dissertation.pdf. Ph.D. Dissertation, University of Michigan. 
Charlow, Nate. 2013a. Conditional preferences and practical conditionals. Linguistics and Philosophy 36: 463-511. doi:10.1007/s10988-013-9143-3.

Charlow, Nate. 2013b. What we know and what to do. Synthese 190: 2291-2323. doi:10.1007/s11229-011-9974-9.

Charlow, Nate. 2014a. Logic and semantics for imperatives. Journal of Philosophical Logic 43: 617-664. doi:10.1007/s10992-013-9284-4.

Charlow, Nate. 2014b. The meaning of imperatives. Philosophy Compass 9: 540-555. doi:10.1111/phc3.12151.

Charlow, Nate. 2015. Prospects for an expressivist theory of meaning. Philosophers' Imprint 15: 1-43.

Charlow, Nate. 2016a. Decision theory: Yes! Truth conditions: No! In N. Charlow \& M. Chrisman (eds.) Deontic Modality, 47-81. Oxford University Press.

Charlow, Nate. 2016b. Triviality for restrictor conditionals. Noûs 50: 533-564. doi:10.1111/nous.12111.

Charlow, Nate. forthcoming. Decision-theoretic relativity in deontic modality. Linguistics and Philosophy .

Condoravdi, Cleo \& Sven Lauer. 2012. Imperatives: meaning and illocutionary force. In C. Pi nón (ed.) Empirical Issues in Syntax and Semantics, vol. 9, 37-58. CSSP Paris.

Cremers, Alexandre \& Emmanuel Chemla. 2016. A psycholinguistic study of the exhaustive readings of embedded questions. Journal of Semantics 33: 49-85. doi:10.1093/jos/ffuo14.

Crnic, Luka \& Tue Trinh. 2008. Embedding imperatives in english. In A. Riester \& T. Solstad (eds.) Proceedings of Sinn und Bedeutung 13. Stuttgart. http://www.ims.uni-stuttgart.de/projekte/sfb-732/sinspec/sub13/crnicTrinh.pdf.

Culicover, Peter W. \& Ray Jackendoff. 1997. Semantic subordination despite syntactic coordination. Linguistic Inquiry 28: 195-217. http://www.jstor.org/stable/4178974.

von Fintel, Kai \& Sabine Iatridou. 2009. Covert modals? One particular case. http://web.mit.edu/fintel/ 1sa220-class-6-handout.pdf. Lecture delivered at LSA 2009, Berkeley.

von Fintel, Kai \& Sabine Iatridou. forthcoming. A modest proposal for the meaning of imperatives. In A. Arregui, M. Rivero \& A. Pablo Salanova (eds.) Modality across syntactic categories. Oxford University Press.

Gibbard, Allan. 1990. Wise Choices, Apt Feelings. Cambridge: Harvard University Press.

Gibbard, Allan. 2003. Thinking How to Live. Cambridge: Harvard University Press.

Ginzburg, Jonathan \& Ivan A. Sag. 2001. Interrogative Investigations: the form, meaning, and use of English interrogatives. Stanford: CSLI Publications.

Han, Chung-hye. 1998. The structure and interpretation of imperatives: Mood and force in universal grammar. http://www.sfu.ca/ chunghye/papers/dissertation.pdf. Ph.D. Dissertation, University of Pennsylvania.

Harris, Daniel W. 2014. Speech act theoretic semantics. http://danielwharris.com/dissertation.pdf. Ph.D. Dissertation, CUNY.

Heim, Irene \& Angelika Kratzer. 1998. Semantics in Generative Grammar. Oxford: Blackwell.

Karttunen, Lauri. 1977. Syntax and semantics of questions. Linguistics and Philosophy 1: 3-44. doi:10.1007/BFoo351935.

Kaufmann, Magdalena. 2012. Interpreting Imperatives. Dordrecht: Springer.

Kaufmann, Magdalena \& Claudia Poschmann. 2013. Embedded imperatives: Empirical evidence from colloquial german. Language 89: 619-637. doi:10.1353/lan.2013.0050.

Kaufmann, Stefan \& Magdalena Schwager. 2011. A unified analysis of conditional imperatives. In E. Cormany, S. Ito \& D. Lutz (eds.) Proceedings of SALT 19, 239-259. Ithaca: CLC Publications. semanticsarchive.net/Archive/ TYzZWYyM/.

Klinedinst, Nathan \& Daniel Rothschild. 2012. Connectives without truth tables. Natural Language Semantics 20: 137-175. doi:10.1007/s11050-011-9079-5.

Kolodny, Niko \& John MacFarlane. 2010. Ifs and oughts. Journal of Philosophy 107: 115-143. doi:10.5840/jphil2010107310.

Kratzer, Angelika. 1981. The notional category of modality. In H. Eikmeyer \& H. Rieser (eds.) Words, Worlds, and Contexts, 38-74. Berlin: De Gruyter.

Kratzer, Angelika. 1991. Conditionals. In A. von Stechow \& D. Wunderlich (eds.) Semantics: An International Handbook of Contemporary Research, 651-656. Berlin: De Gruyter.

Kratzer, Angelika. 2012. Modals and Conditionals. Oxford: Oxford University Press.

Lepore, Ernest \& Matthew Stone. forthcoming. Explicit indirection. In D. Fogal, D. Harris \& M. Moss (eds.) New Work on Speech Acts. Oxford University Press.

Lewis, David. 1979. A problem about permission. In E. Saarinen, R. Hilpinen, I. Niiniluoto \& M. B. Provence Hintikka (eds.) Essays in Honour of Jaakko Hintikka, 163-179. Dordrecht: D. Reidel.

Lewis, David. 1980. Index, context, and content. In S. Kanger \& S. Ohman (eds.) Philosophy and Grammar, 79-100. Holland: D. Reidel.

Mauck, Simon, Miok Pak, Paul Portner \& Raffaella Zanuttini. 2005. Imperative subjects: A cross-linguistic perspective. In C. Brandstetter \& D. Rus (eds.) Georgetown University Working Papers in Theoretical Linguistics, 135-152. http://faculty.georgetown.edu/portnerp/nsfsite/MPPZ.pdf.

Montague, Richard. 1973. The proper treatment of quantification in ordinary English. In Jaakko Hintikka, Julius Moravcsik \& Patrick Suppes (eds.) Approaches to Natural Language: Proceedings of the 1970 Stanford Workshop on Grammar and Semantics, 221-242. Dordrecht: D. Reidel. Reprinted in Formal Philosophy, by Richard Montague, Yale University Press, New Haven, 1974, pages 247-270. 
Nate Charlow

Moss, Sarah. 2015. On the semantics and pragmatics of epistemic modals. Semantics and Pragmatics 8: 1-81.

Ninan, Dilip. 2010. Semantics and the objects of assertion. Linguistics and Philosophy 33: 355-380. doi:10.1007/s10988-011-9084-7.

Parsons, Josh. 2013. Command and consequence. Philosophical Studies 164: 61-92. doi:10.1007/s11098-013-0094-x.

Portner, Paul. 2004. The semantics of imperatives within a theory of clause types. In Robert B. Young (ed.) Proceedings of SALT 14, 235-252. CLC Publications. http://semanticsarchive.net/Archive/mJlZGQ4N/.

Portner, Paul. 2007. Imperatives and modals. Natural Language Semantics 15: 351-383. doi:10.1007/s11050-0079022-y.

Portner, Paul. 2012. Permission and choice. In G. Grewendorf \& T. Zimmermann (eds.) Discourse and Grammar: From Sentence Types to Lexical Categories. Studies in Generative Grammar, Mouton de Gruyter. http: //semanticsarchive.net/Archive/jI1YjMyY/.

Portner, Paul. forthcominga. Commitment to priorities. In D. Fogal, D. Harris \& M. Moss (eds.) New Work on Speech Acts. Oxford University Press.

Portner, Paul. forthcomingb. Imperatives. In M. Aloni \& P. Dekker (eds.) Cambridge Handbook of Formal Semantics. Cambridge University Press. http://www.semanticsarchive.net/Archive/jgzNDdhM/.

Roberts, Craige. 1996. Information structure in discourse: Towards an integrated formal theory of pragmatics. In OSU Working Papers in Linguistics, Vol 49: Papers in Semantics. Ohio State University. http://semanticsarchive. net/Archive/WYzOTRkO/.

Roberts, Craige. 2015. Conditional plans and imperatives: A semantics and pragmatics for imperative mood. In T. Brochhagen, F. Roelofsen \& N. Theiler (eds.) Proceedings of the 2oth Amsterdam Colloquium, 353-362. University of Amsterdam: Institute for Logic, Language, and Computation.

Roberts, Craige. forthcoming. Speech acts in discourse context. In D. Fogal, D. Harris \& M. Moss (eds.) New Work on Speech Acts. Oxford University Press.

Rothschild, Daniel. 2012. Expressing credences. Proceedings of the Aristotelian Society CXII, Part 1: 99-114. doi:10.1111/j.1467-9264.2012.00327.x.

Sadock, Jerrold M. \& Arnold M. Zwicky. 1985. Speech act distinctions in syntax. In T. Shopen (ed.) Language typology and syntactic description: Clause structure. Cambridge University Press.

Schroeder, Mark. 2011. Ought, agents, and actions. The Philosophical Review 120: 1-41. doi:10.1215/00318108-2010017.

Schwager, Magdalena. 2007. Conditionalized imperatives. In M. Gibson \& J. Howell (eds.) Proceedings of SALT 16, 241-258. Ithaca: CLC Publications.

Searle, John R. 1975. Indirect speech acts. In P. Cole \& J. Morgan (eds.) Syntax and Semantics Volume 3: Speech Acts, 59-82. New York: Academic Press.

Stalnaker, Robert. 2002. Common ground. Linguistics and Philosophy 25: 701-721. doi:10.1023/A:1020867916902.

Starr, William B. forthcoming. A preference semantics for imperatives. Semantics and Pragmatics .

Swanson, Eric. 2006. Interactions with context. http://www-personal.umich.edu/ ericsw/Swanson, \%2oInteractions\%20with\%20Context.pdf. Ph.D. Dissertation, MIT.

Swanson, Eric. forthcoming. The application of constraint semantics to the language of subjective uncertainty. Journal of Philosophical Logic doi:10.1007/s10992-015-9367-5.

Vranas, Peter B. M. 2008. New foundations for imperative logic I: Logical connectives, consistency, and quantifiers. Noûs 42: 529-572.

Vranas, Peter B. M. 2010. In defense of imperative inference. Journal of Philosophical Logic 39: 59-71. doi:10.1007/s10992-009-9108-8.

Willer, Malte. 2012. A remark on iffy oughts. Journal of Philosophy 109: 449-461. doi:10.5840/jphil2012109719.

Willer, Malte. 2014. Dynamic thoughts on ifs and oughts. Philosophers' Imprint 14: 1-30.

Wilson, Deirdre \& Dan Sperber. 1988. Mood and the analysis of non-declarative sentences. In J. Dancy, J. Moravcsik \& C. Taylor (eds.) Human agency: Language, duty and value, 77-101. Stanford: Stanford University Press.

Yalcin, Seth. 2011. Nonfactualism about epistemic modality. In Andy Egan \& Brian Weatherson (eds.) Epistemic Modality, 295-332. Oxford: Oxford University Press.

Yalcin, Seth. 2012a. Bayesian expressivism. Proceedings of the Aristotelian Society CXII, Part 2: 123-160. doi:10.1111/j.1467-9264.2012.00329.x

Yalcin, Seth. 2012b. A counterexample to modus tollens. Journal of Philosophical Logic 41: 1001-1024. doi:10.1007/s10992-012-9228-4.

Yalcin, Seth. 2014. Semantics and metasemantics in the context of generative grammar. In A. Burgess \& B. Sherman (eds.) Metasemantics: New Essays on the Foundations of Meaning, 17-54. Oxford University Press.

Yalcin, Seth. forthcoming. Expressivism by force. In D. Fogal, D. Harris \& M. Moss (eds.) New Work on Speech Acts. Oxford University Press. 